\title{
AUTOMATIC TSUNAMI EARLY WARNING SYSTEM TERSINKRONISASI BMKG DAN PENGERAS SUARA TEMPAT IBADAH
}

\author{
Riza Atika ${ }^{1}$, Anung Endra Raditya ${ }^{2}$, Rohsan Nur Marjianto ${ }^{3}$ \\ 1,2,3 Jurusan Pendidikan Teknik Elektro FT UNY \\ Email: rizaatika.2018@student.uny.ac.id
}

\begin{abstract}
Indonesia is a country prone to tsunamis because it is located at the confluence of three main plates of the world such as Eurasia, Indo-Australia and the Pacific and is passed by an active mountain ring or ring of fire. Making the Automatic Tsunami Early Warning Synchronized BMKG and Loudspeakers Places of Worship aim as a means of delivering potential tsunami hazards quickly and automatically to the community. The method used is research and development. How it works Automatic Tsunami Early Warning System uses Arduino Uno and GSM SIM modules as the main system. The LCD and dot matrix displays are used as earthquake potential data viewers in written form. Potential earthquake data on the official website of BMKG, namely data.bmkg.go.id/xml as the trigger, will be downloaded by Arduino Uno and sent using a GSM SIM module and the potential tsunami data is parsed and sent to locations potentially affected by the tsunami. Automatic Tsunami Early Warning System has successfully delivered information on the average delivery time of 13.48 seconds.
\end{abstract}

Keywords: tsunami, dissemination, automatic

\begin{abstract}
ABSTRAK
Indonesia adalah negara yang rawan akan tsunami karena terletak di pertemuan tiga lempeng utama dunia seperti Eurasia, Indoaustralia dan Pasifik serta dilewati barisan gunung aktif atau ring of fire. Pembuatan Automatic Tsunami Early Warning Tersinkronisasi BMKG dan Pengeras Suara Tempat Ibadah bertujuan sebagai alat penyampaian adanya potensi bahaya tsunami secara cepat dan otomatis ke masyarakat. Metode yang digunakan adalah penelitian dan pengembangan. Cara kerja Automatic Tsunami Early Warning System menggunakan Arduino Uno dan modul GSM SIM sebagai sistem utamanya. LCD dan diplay dot matrix digunakan sebagai penampil data potensi gempa dalam bentuk tulisan. Data potensi gempa pada website resmi milik BMKG yaitu data.bmkg.go.id/xml sebagai pemicunya yang akan diunduh oleh Arduino Uno dan dikirim menggunakan modul GSM SIM kemudian data potensi tsunami tersebut diparsing dan dikirim ke lokasi-lokasi yang berpotensi terdampak tsunami. Automatic Tsunami Early Warning System telah berhasil menyampaikan informasi kecepatan waktu pengiriman rata-rata sebesar 13,48 sekon.
\end{abstract}

Kata kunci: tsunami, diseminasi, otomatis

\section{PENDAHULUAN}

Indonesia terletak di pertemuan tiga lempeng utama dunia yaitu Eurasia, Indoaustralia dan Pasifik serta dilewati barisan gunung api aktif atau ring of fire sehingga berpotensi bencana khususnya gempa hingga tsunami.

Bencana tsunami yang terjadi pada tanggal 28 September 2018 lalu menyisakan luka mendalam dan menjadi bencana nasional karena memakan 2.101 orang meninggal,
1.373 orang hilang dan 206.219 orang terpaksa mengungsi. Sedangkan di penghujung tahun 2018, tepatnya pada tanggal 22 Desember 2018 terjadi tsunami Selat Sunda yang menghantam Banten dan lampung hingga memakan 281 orang meninggal, 1.016 orang terluka dan 11.687 orang terpaksa mengungsi.

Bakornas PB (2007) menjelaskan bahwa tsunami dapat diartikan sebagai gelombang laut dengan periode panjang yang ditimbulkan oleh gangguan impulsif dari dasar laut. Gangguan impulsif tersebut dapat berupa 
gempa tektonik, erupsi vulkanik atau longsoran.

Badan Nasional Penanggulangan Bencana (BNPB) menyatakan Indonesia masih kekurangan sirene dan buoy (alat deteksi tsunami). Berdasarkan data BMKG, jumlah sirene tsunami di seluruh Indonesia hanya berjumlah sekitar 255 unit. Dari jumlah itu, 55 unit diantaranya milik BMKG dan 200-an unit lainnya milik komunitas lain. Padahal secara keseluruhan, wilayah Indonesia idealnya membutuhkan sirene tsunami sebanyak seribu unit.

Berdasarkan UU No. 24 tahun 2007 tentang Penanggulangan Bencana, penyelenggaran penanggulangan bencana adalah serangkaian upaya yang meliputi penetapan kebijakan pembangunan yang berisiko timbulnya bencana, kegiatan pencegahan bencana, tanggap darurat dan rehabilitasi. Kegiatan pencegahan bencana adalah serangkaian kegiatan yang dilakukan sebagai upaya untuk menghilangkan /mengurangi ancaman bencanna.

Alat peringatan dini tsunami yang sudah ada yaitu InaTEWS (Indonesia Tsunami Early Warning System) milik BMKG dan EWS (Early Warning System) milik BPBD. Sayangnya alat peringatan dini tsunami yang sudah ada seperti InaTEWS membutuhkan waktu aktivasi bagian server yang memakan waktu 3-5 menit padahal golden time atau waktu emas untuk evakuasi tsunami hanya berlangsung selama 10 menit.

InaTEWS juga rawan akan tindakan vandalisme, kerusakan kabel salah satunya karena hewan pengerat, korosif karena wadah yang terbuat dari besi ditempatkan diluar ruangan tanpa atap, perawatannya jauh lebih mahal dibanding pengadaannya, komponen cadangan yang sulit dicari karena buatan Amerika dan sudah tidak diproduksi lagi.

Penyampaian informasi potensi tsunami di Indonesia masih manual karena membutuhkan keputusan kepala sistem peringatan dini yang sedang bertugas. Kemudian informasi potensi tsunami tersebut dikirim melalui faxsimile ke instansi-intansi terkait seperti BPBD (Badan Penanggulangan Bencana Daerah), Polri dan TNI menerima pesan peringatan dini tsunami dan segera meresponnya termasuk media diminta segera menginterupsikan siaran melalui radio dan televisi. PUSDALOPS (Pusat Pengendali Informasi) yang memiliki wewenang untuk menyalakan sistem peringatan dini tersebut.

PUSDALOPS yang bertanggungjawab sebagai pengelola informasi bencana (Disaster Information Manager) mempunyai wewenang untuk menyalakan sirene peringatan dini tsunami baik milik BMKG yaitu InaTEWS (Indonesia Tsunami Early Warning System) sebagai media desiminasi atau penyampaian informasi bahaya tsunami kepada masyarakat sekitar pesisir pantai Bantul dan kabupaten Kulon Progo serta milik pemerintah Bantul yaitu BISS (Bantul Integrated Sirine System).

Dalam pengaktivasian BISS prosesnya berantai dari BMKG ke BPBD kemudian disiarkan menggunakan gelombang radio seperti HT (Handy Talky) pada frekuensi 140450 megaherzt sehingga membutuhkan power pemancar besar, memiliki kelemahan terhadap cuaca, transmisi data rentan terhadap intervensi sinyal radio lain yang berdekatan, keterbatasan bandwidth dan harus selalu ON sehingga biaya pembuatan dan perawatan relatif lebih mahal.

Oleh karenanya, solusi untuk menyampaikan informasi potensi dini tsunami secara lebih cepat dengan Automatic Tsunami Early Warning System Tersinkronisasi BMKG dan Pengeras Suara Tempat Ibadah yang merupakan inovasi alat peringatan dini tsunami yang otomatis menggunakan Modul GSM SIM900A dan Arduino Uno sebagai sistem utamanya untuk mengunduh data potensi tsunami pada website resmi BMKG yaitu data.bmkg.go.id kemudian dicek dan dikirim ke lokasi-lokasi yang terdampak.

Keuntungan dari Automatic Tsunami Early Warning System ini adalah lebih cepat karena tidak membutuhkan banyak perantara instansi terkait untuk menyampaikan informasi potensi tsunami, tidak menimbulkan kesenjangan 
infomasi karena dapat didengar dan diketahui oleh berbagai segmen masyarakat berbeda dengan potensi tsunami yang hanya diberitahu melalui aplikasi di smarthphone karena tidak semua orang memiliki smartphone. Tujuan dari diciptakannya alat ini adalah untuk menyampaikan informasi adanya potensi tsunami secara cepat dan akurat.

\section{METODE}

Metode yang dilakukan dalam pengembangan Automatic Tsunami Early Warning System yaitu R\&D (Research and Development) atau Penelitian dan Pengembangan. Terdapat empat tahapan, yaitu sebagai berikut:

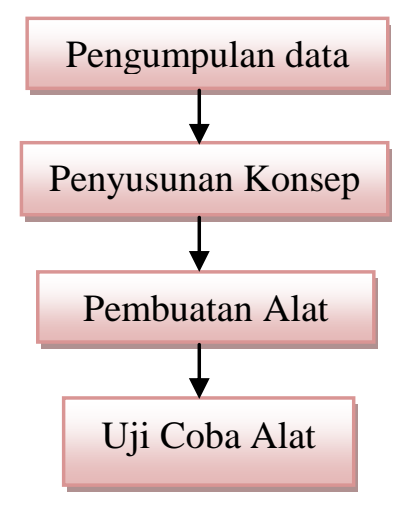

Gambar 1. Metode R \& D

Tahap pertama: pengumpulan data melakukan studi literatur dan diskusi dengan dosen pembimbing. Kemudian melakukan observasi dan wawancara ke instansi-instansi terkait seperti Stasiun Geofisika Yogyakarta, BPBD Bantul dan BPBD Kulon Progo untuk menjamin keakuratan data mengenai mekanisme alat penyampaian informasi potensi tsunami yang sudah ada dan kendala apa saja yang dimiliki.

Tahap kedua: pengumpulan dasar teori dari komponen yang dibutuhkan untuk membuat Automatic Tsunami Early Warning System berdasar jurnal-jurnal yang sudah ada.

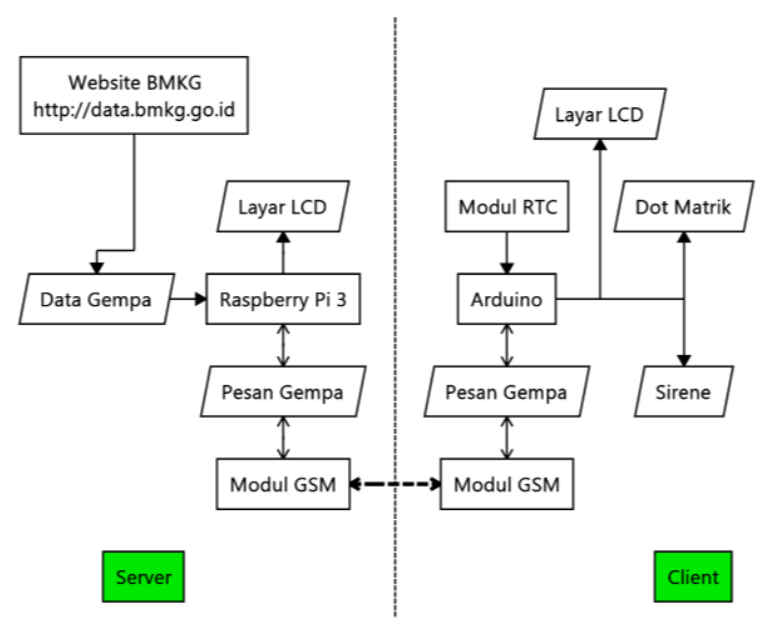

Gambar 2. Flowchart alur kerja alat

Sistem peringatan dini tsunami ini terdiri dari dua alat yang terpasang pada tempat yang berbeda, pada sisi server yang diletakkan di pusat kota yang memiliki akses internet memadai menggunakan Raspberry Pi sebagai komputer server yang mengambil data dari website resmi BMKG, kemudian modul GSM sebagai media pengiriman SMS, serta layar LCD untuk memantau aktifitas dari komputer server. Pada sisi client, digunakan mikrokontroler Arduino sebagai pengendali utama dalam penyalaan sirine dan penampil informasi gempa pada dot-matrix dan layar LCD.

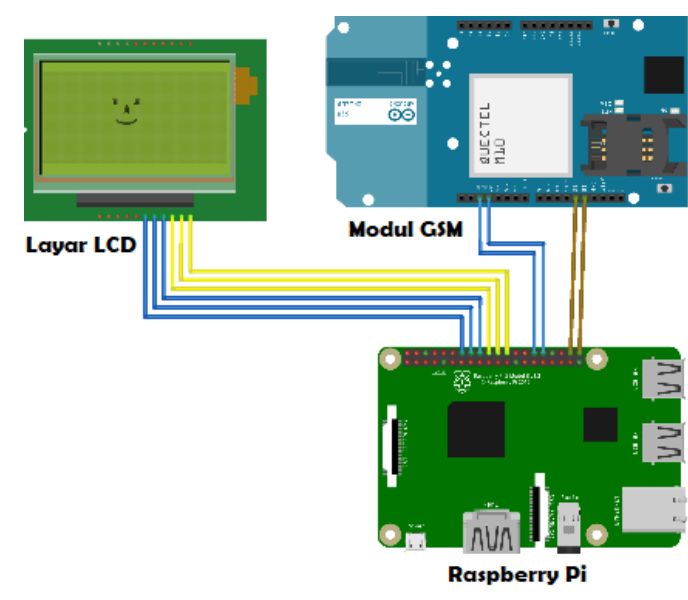

SISI SERVER

(a) 


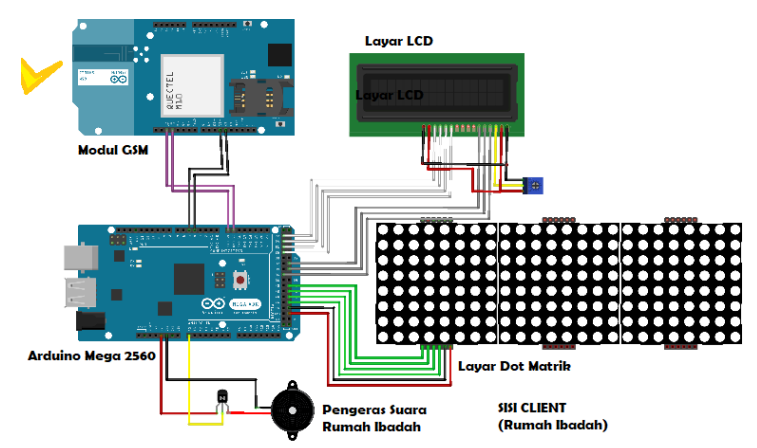

(b)

Gambar 3. Desain pengkabelan komponen (a) server, (b) client

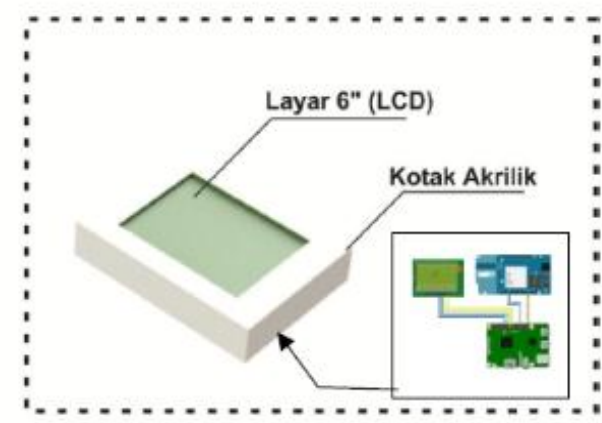

(a)

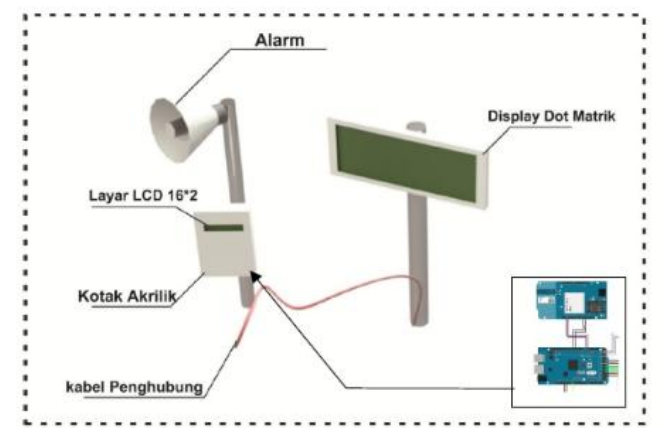

(b)

Gambar 4. Desain Box dan Panel Alat (a) Server (b) Client

Tahap ketiga: pembuatan dan perakitan alat. Dalam tahapan ini hal pertama yang dilkakukan adalah persiapan peralatan dan bahan. Adapun bahan utama yang digunakan adalah mikrokontroler Arduino Uno, LCD 20x4, Modul GSM SIM dan display dot matrix. Setelah Automatic Tsunami Early Warning System sudah tercipta dilakukan pengujian dan evaluasi dalam rangka penyempurnaan alat. Pengujian alat dilakukan untuk mengetahui kecepatan pengiriman data potensi gempa dan penerimaannya apakah berhasil memicu sirene untuk berbunyi.

Tahap keempat: pengujian alat yang dilakukan di Aula Robotika, Fakultas Teknik, Universitas Negeri Yogyakart dan Masjid AsSalam. Pengujian dimaksudkan untuk mengetahui unjuk kerja alat yang sudah dibuat. Pengujian dilakukan dengan website dummy atau website replika BMKG yaitu data.bmkg.go.id yang dibuat dengan bahasa xml karena alat mitigasi bencana ini tidak memungkinkan untuk menunggu terjadinya tsunami secara nyata.

Analisis dilakukan terhadap hasil dari pengujian Automatic Tsunami Early Warning System sehingga dapat mengetahui kekurangan alat. Dari analisis dapat dilakukan evaluasi untuk menyempurnakan alat yang telah diciptakan sehingga dapat menyampaikan informasi potensi tsunami secepat mungkin.

\section{HASIL DAN PEMBAHASAN}

\section{Hasil}

Alat Automatic Tsunami Early Warning System dapat mengunduh data potensi gempa dari website BMKG dan memprosesnya untuk memcu bunyi sirene pada pengeras suara tempat ibadah. Pembuatan alat ini dilakukan secara tim yang dibagi sesuai dengan tugasnya. Sehingga alat yang dibuat selesai dengan baik dan sesuai jadwal pelaksanaan. Hasil dari pengembangan alat ini dapat dilihat pada photo yang disajikan pada jurnal ini.

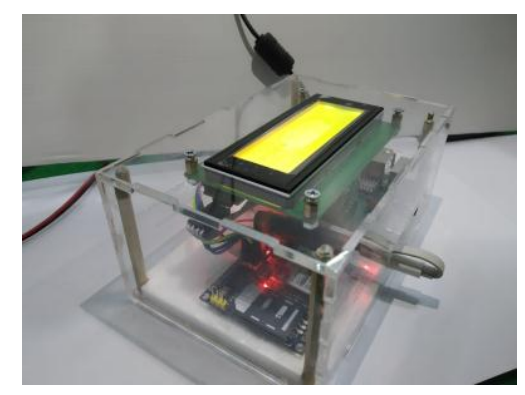

Gambar 5. Bagian server 


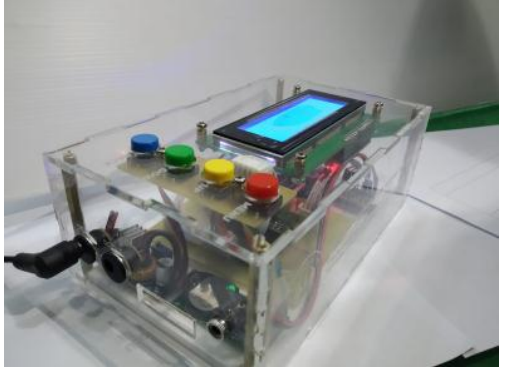

Gambar 6. Bagian client

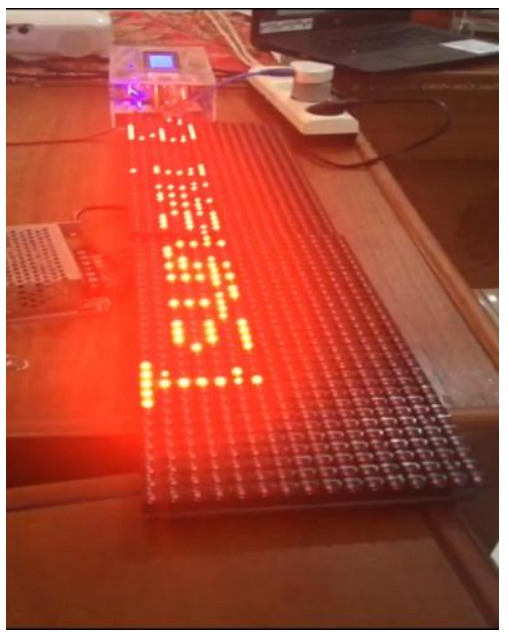

Gambar 7. Tampilan dot matrix

Pengujian alat peringatan dini tsunami otomatis yaitu Automatic Tsunami Early Warning System yang telah melalui tahap uji coba dan evaluasi berkali-kali selama sebulan dengan hasil menyampaikan informasi potensi tsunami dari website dummy atau replika BMKG. Adapun dari hasil pengujian didapatkan:

Tabel. 1 Hasil uji coba alat terhadap waktu kecepatan pemrosesan data

\begin{tabular}{llcl} 
No. & $\begin{array}{c}\text { Uji Coba } \\
\text { Alat }\end{array}$ & Waktu & Sirene \\
\hline 1. & Pertama & $13,8 \mathrm{~s}$ & Berbuyi \\
2. & Kedua & $12,2 \mathrm{~s}$ & Berbuyi \\
3 & Ketiga & $14,5 \mathrm{~s}$ & Berbuyi \\
4. & Keempat & $13,4 \mathrm{~s}$ & Berbuyi \\
5. & Kelima & $13,5 \mathrm{~s}$ & Berbuyi \\
\hline \multicolumn{3}{r}{ Rata-rata } & $\mathbf{1 3 , 4 8}$ \\
\multicolumn{4}{c}{$\mathbf{s}$} \\
\hline
\end{tabular}

\section{Pembahasan}

Berdasarkan data pengujian yang telah dilakukan, Automatic Tsunami Early Warning System mempunyai beberapa kelebihan yaitu :

1. Kecepatan pemrosesan data stabil Automatic Tsunami Early Warning System dapat menyampaikan informasi secara cepat. Dilihat dari hasil uji coba yang menunjukkan rata-rata waktu pengiriman sampai sirine berbunyi yaitu 13,48 detik.

2. Lebih efisien energi

Automatic Tsunami Early Warning System cukup menggunakan catu daya $5 \mathrm{~V}$ saat kondisi siaga (standby), sehingga tidak membutuhkan daya listrik yang besar seperti halnya Tsunami Early Warning System lain yang telah terpasang yang menggunakan radio frekuensi berdaya listrik besar.

3. Maintenance mudah

Biaya perawatan Automatic Tsunami Early Warning System jauh lebih mudah dibanding perawatan alat peringatan dini tsunami yang sudah ada karena ukurannya yang pun jauh lebih kecil.

4. Valid dan akurat

Data potensi gempa berasal dari 170 seismograf yang berada di daratan milik BMKG yang masuk ke website resmi BMKG yaitu http://data.bmkg.go.id., sehingga keakuran data terkait peringatan tidak dairagukan lagi sumbernya.

5. Mudah diaplikasikan

Pemanfaatan pengeras suara tempat ibadah yang tersebar disekitaran pantai dapat dipasangi alat ini, yang dibuat dengan mudah dalam pemsangannya.

\section{SIMPULAN}

Automatic Tsunami Early Warning System adalah alat peringatan dini tsunami otomatis yang bekerja dengan cara mengunduh data potensi gempa dalam bentuk xml dari website resmi milik BMKG yaitu data.bmkg.go.id menggunakan mikrokontroler 
Arduino Uno kemudian data potensi gempa tersebut dipecah dan dikirim ke lokasi-lokasi yang berpotensi akan terdampak tsunami menggunakan Modul GSM SIM untuk menyalakan sirene tempat ibadah yang berada di lokasi tersebut agar masyarakat dapat segera melakukan evakuasi secepat mungkin.

Setelah Automatic Tsunami Early Warning System mendapat hak cipta dan kedepannya dilakukan pengembangan lagi untuk dipatenkan, diharapkan alat ini dapat membantu seluruh masyarakat khususnya masyarakat Indonesia yang hidup di lokasi rawan tsunami untuk meminimalisir jatuhnya korban jiwa lebih banyak.

\section{DAFTAR PUSTAKA}

BBC News Indonesia. 2018. Deretan Bencana Alam Mematikan yang Menerjang Indonesia Sepanjang 2018. Diakses melalui

https://www/bbc.com/indonesia/majalah -46691586 pada tanggal 15 Juni 2019.

detikNews. 2018. Update Data Korban Tsunami Selat Sunda : 281 Tewas, 1.016
Luka. Diakses melalui https://news.detik.com/berita/d-

4356766/update-data-korban-tsunamiselat-sunda-281-tewas-1016-luka pada tanggal 15 Juni 2019

BAKORNAS PB. 2007. Pengenalan Karakteristik Bencana dan Upaya Mitigasinya di Indonesia : Edisi II. Diakses melalui https://www.cnnindonesia.com/nasional/ 20160303195458-20-115215/bnpbindonesia-kekurangan-sirene-dan-alatdeteksi-tsunami pada tanggal 18 Juni 2019

Republik Indonesia. 2007. UU No. 24 Tahun 2007 tentang Penanggulangan Bencana. Sekretariat Negara. Jakarta.

Kaur, Navreet, Harwinder Singh Sohal. 2014. XML Parsing on Multicore Processors and Data Representation in NET Tree Control International Journal of Computer Applications. Volume 99-No. 18, August 2014. 